\title{
Acil Durum ve Afet Müdahale Çalışanlarının Mobbing Algısı ve Demografik Değişkenlere Göre Farklılıklar: Gümüşhane İli Örneği
}

\author{
The Mobbing Perception of Emergency and Disaster Response Employees \\ and Differences According to Demographic Variables: An Example of The \\ City of Gümüşhane
}

\begin{abstract}
Öz
Bu araştırma, acil durum ve afet müdahale çalı̧̧anlarının maruz kaldı ̆̆ mobbing düzeyini belirlemek ve demografik değişkenlere göre mobbing düzeyinin faklılık gösterip göstermediğini tespit etmek amacıyla yapılmıştır. Araştırma evreni, Gümüşhane Kamu Hastaneler Birliğine (GKHB) bağh Gümüşhane Devlet Hastanesi, Kelkit Devlet Hastanesi, Şiran Devlet Hastanesi, Gümüşhane Ill Afet ve Acil Durum Müdürlüğ̈̈, Gümüşhane İl İtfaiye Müdürlüğü, Gümüşhane il merkezi ve ilçelerde bulunan 112 istasyonlarında çalışan toplam 332 kişidir. Anket 08/05/2017 22/05/2017 tarihleri arasında yapılmıştır ve toplamda 140 kişi analize dahil edilmiştir. Analiz sonucunda araştırma kapsamındaki çalışanların mobbing algilama düzeylerinin çok düşük olduğu tespit edilmiştir. Mobbing algılama düzeyleri cinsiyet, eğitim durumu, gelir durumu, çalışma saatleri ve çalışlan kuruma göre farklllık göstermektedir. Mobbing algılama düzeyinin çok düşük olması bu seviyedeki grupsal farkllıkların yorumlanmasında sıkıntılar doğurmuştur ve genellemeye gidilmemiştir.
\end{abstract}

\section{Abstract}

This research was conducted to determine the level of mobbing that emergency and disaster response workers are exposed to and to determine whether the mobbing level differs according to demographic variables. The population of the research is 332 people working in Gümüşhane State Hospital, Kelkit State Hospital, Şiran State Hospital, Gümüşhane Provincial Directorate of Disaster and Emergency, Gümüşhane Provincial Fire Department, Gümüşhane city center and 112 stations in the districts of Gümüşhane Public Hospitals Association (GKHB). The survey was conducted between 08/05/2017 - 22/05/2017 and a total of 140 people were included in the analysis. As a result of the analysis, it was determined that the mobbing perception levels of the employees within the scope of the study were very low. Perception levels of mobbing differ according to gender, education level, income level, working hours and the institution they work for. The low level of perception of mobbing caused difficulties in interpreting the group differences at this level and generalization was not made.

\section{Giriş}

Mobbing çalışma hayatında özellikle de hizmet sektörünün insanlarla birebir iletişimde bulunanlarda ortaya çıkabilen, çalışanların psikolojik yapılarına zarar verip performanslarını düşüren, kaynağı örgütsel yapı, çalışma alanları ve örgütün işleyiş düzeni gibi faktörler olan bir kavramdır (Öztürk vd., 2015: 32). Taraflardan birinin çatışmayı çözmek için karşı tarafa gücünü, yetkisini ve otoritesini kullanması ve zorlaması durumlarında ortaya çıkabilir (Turan vd, 2015).

Kısaca duygusal saldırı olarak adlandırılabilecek olan mobbing kavramı, bir kişi veya bir grubun diğer bir kişi veya gruba karşı kötü niyetli (ima etme, dalga geçme, itibar zedeleme, cinsel 
tacizde bulunma, saldırgan hareketler gibi) davranışlarının bütününe verilen bir isimdir. Psikolojik bir şiddet türü olup asıl amaç tavır alınan bireyin sindirilmesi veya ondan bir menfaat temin edilmesi için gözünün korkutulmasıdır. Genellikle işten çıkmayla sonuçlanabilmektedir (Fettahlığlu, 2008: 9).

Mobbing davranışları 5 ana faktör altında toplanabilir. İletişim ve ifadeyi kısıtlayıcı davranışlar; bu davranış türünde amaç çalışanın diğerler çalışanlarla, çalışanın amirleriyle ve diğer çalışma arkadaşlarıyla iletişimde bulunmasını engellemektir. Sosyal ilişkiyi engelleyici davranışlar; bu davranış türündeki amaç ise çalışanın diğer insanlarla sosyalleşmesini onlarla birlikte vakit geçirmesini engellemektir. Kişisel itibar zedeleyen davranışlar; bu davranış türündeki amaç birebir çalışanın şahsi karakterini zaafa uğratmaktır. Mesleki itibarı engelleyici davranışlar; bu davranış türündeki amaç ise çalışanın yaptığı işin kötü gösterilmesi ve kariyerinin engellenmesidir. Kişisel sağlığa zarar veren davranışlar: bu davranış türündeki amaç ise çalışanın psikolojisini bozmaktır (Karçın, 2016: 7).

Mobbing 5 aşamalı bir süreç halinde meydana çıkar: Birinci aşama çatışma aşaması olup, bu aşamada mobbing henüz başlangıç sürecinde olup, maruz kalana karşı farklı lakaplar takma, iş ortamıyla iletişimin engellenmesi, gereksiz işlerin verilmesi gibi davranışlar görülür. İkinci aşama saldırganlık aşaması olup bu aşamada çalışanın ortamdan daha fazla izole edilmesi için daha fazla tacizde bulunulur, çalışan yoksayılır, konuşması engellenir ve aşağılanır. Üçüncü aşama yönetimin devreye girme aşaması olup, bu aşamada yönetim çalışanın tacize uğramasını kuruntu olarak görür ve tacize kendiside ortak olur. Dördüncü aşama damgalama aşaması olup, çalışanın profesyonel yardım alma isteği ve tutumu çalışanın damgalanmasıyla sonuçlanır. Beşinci aşama işten çıkarılma aşamasıdır. Bu aşamada çalışan boyun eğdirilip emekli olması veya işten istifa etmesi istenilir (Kehribar vd., 2017: 5).

Mobbing uygulayanların farklı karakterde kişilikleri olduğu bunların bir grupta toplanamayacağı tespit edilmiş olup, genel tiplemeler şu şekildedir; fesatçı, hiddetli, kendini begenmiş, sadist, dalkavuk, zorba, korkak, eleştirici, hayal kırıklığına uğramış. Mobbinge maruz kalanlarında genel bir tipolojileri olmayıp bunlar dört grupta toplanabilirler; yeni gelen, farklı olan, başarılı olan ve yalnız olan. Mobbing olayına tanık olanların alacakları tavırlara göre gruplandırılır ise; diplomatik izleyici, yardakçı izleyici, fazla ilgili izleyici, hiçbirşeye karışmayan izleyici ve iki yüzlü yılan izleyici (Tetik, 2010: 84-85).

Mobbing olayında en fazla etkilenen unsur mobbinge maruz kalan bireydir. Mobbingin etkileri bir anda ortaya çıkmaz yavaş ve sinsi bir şekilde ortaya çıkar ve bireye zarar verir. Bu zararlar ekonomik ve sosyal zararlardır. Bireyin sağlık için harcayacağı miktar ve işten ayrılması sonucu doğan zarar ekonomik zararlardandır. Çalıştığı yerden dışlanmış birey zamanla sosyal çevresi ve ailevi ortamından da dişlanabilir. Dişlanmazsa bile birey bozulan psikolojisi nedeniyle bir dışlanmışlık algısı yaşar. Kendini yalnızlık içinde hisseder. Bireyin üzerinde oluşan psikolojik ve sosyal zararlar ekonomik zararlardan çok daha etkili olabilir. Birey depresyon, panik atak, anlamsız korku ve heyecanlar, taşikardi, yüksek tansiyon, titreme, baş ağrısı, iştahsızlık, zayıflama ve terkedilmiş duygusu yaşayabilir (Tınaz, 2006: 16-17).

Mobbinge sebep olan örgütsel ve yönetimsel sebepler şunlardır; Psikolojik baskının işgörme yöntemi olarak görülmesi, işten çıkarmayla elde edilecek maliyet avantajı, iletişim kanallarının yanlış kurulması veya kullanılması, işletmede sorun çözme ve yönetim anlayışlarındaki yanlışlıklar ve eksiklikler, yönetici konumundakilerin bilgisizlikleri veya kötü niyetleri, bireyler arası ilişkilerle ilgili yanlış kültürel alışkanlıklar, takım çalışmasının yanlış anlaşılması veya uygulanması ve iş içi eğitimin eksik olması veya olmaması (Gültekin ve Deniz, 2016: 3).

Mobbing olayında iki taraf vardır; güçlü olan ve zayıf olan. Güçlü olan kişinin gücünün farklı kaynakları olabilir (statüsü, baskın karakteri, sosyal ilişkileri vb), zayıf olanında zayıf olmasının da farklı nedenleri olabilir (işte yeni olması, zayıf karakter, zayıf insan ilişkileri vb). Güçlü olan mevkisinin tehlikede olabileceği, kendinden daha yetenekli birinin geldiğini düşünmesi, kıskançlık, kötü kişilik gibi nedenlerden dolayı zayıf olanı taciz eder ve bu tacizinde çoğu zaman ispatlanması zordur. Çünkü güçlü olan elindeki olanakları kullanarak ispatı engelleyebilir (Demirbulat, 2012: 29). 
Mobbinge maruz kalma süresi ve sıklığı kişilerde tedavi gerektirecek hasarlara neden olabilir. Eğer mobbinge her gün maruz kalınırsa bu kişilerin \%50'den fazlasının tedavi görmesi gerekir. Ayda bir mobbinge maruz kalanların ise $\% 30^{\prime} u$ civarındakilerin tedavi görmesinin gerekmekte olduğu tespit edilmiştir (Polat ve Pakiş, 2012: 213).

Hukuk bağlamında mobbing olayında üç faktörün önemi vurgulanmıştır. Bunlar; mobbingi uygulayan kişinin amacına bakılmaksızın mobinge uğrayan kişide oluşan etkiler, bu etkilerin mobbinge uğrayana zarar verip vermediği ve mobbing eyleminin sürekliliğidir (Özkul ve Çarıkçı, 2010: 484).

Araştırmanın birinci bölümünde kavramsal çerçeve çizilmiş, ikinci bölümünde materyal metoda yer verilmiş, üçüncü bölümünde bulgular ifade edilmiş ve son olarak sonuç ve değerlendirme kısmı yapılmıştır.

\section{Materyal Metod}

Bu araştırma; Gümüşhane ili merkez ve ilçelerinde görev alan acil durum ve afet müdahale çalışanlarının mobbing açısından durumlarının değerlendirilmesi amacıyla yapılmıştır. Araştırma deseni tanımlayıcı ve çıkarımsal olarak planlanmıştır. Araştırmanın evrenini Gümüşhane Devlet Hastanesi, Kelkit Devlet Hastanesi, Şiran Devlet Hastanesi, Gümüşhane İl Afet Ve Acil Durum Müdürlüğü, Gümüşhane İl İtfaiye Müdürlüğü, Gümüşhane il merkezi ve ilçelerde bulunan 112 istasyonlarında çalışan sağlık personelleri ile birlikte acil durum ve afet müdahale personelleri oluşturmuştur. Araştırma 140 çalışan personel ile tamamlanmıştır. Araştırmanın yapıldığı günlerde izinli ve raporlu olan ve araştırmaya katılmayı kabul etmeyen kişiler araştırmaya dahil edilmemiştir. Tam sayım yöntemi kullanılmıştır. Araştırma 08.05.2017-22.05.2017 tarihleri arasında yürütülmüştür. Verilerin toplanmasında "Kişisel Bilgi Formu ve Acil Durum ve Afet Müdahale Çalışanlarının Mobbing Düzeyi Belirleme" anketi kullanılmıştır.Araştırmacı tarafından literatür bilgileri ışığında geliştirilen bu formun birinci bölümünde, personellerin tanıtıcı özelliklerinden oluşan (yaş, cinsiyet, eğitim düzeyi, sahada karşılaşılan problemlerle ilgili sorular) 17 soru yer almıştır. İkinci bölümünde acil durum ve afet müdahale çalışanlarının karşılaştıkları mobbing problemiyle ilgili olan bir ölçek yer almaktadır. Bu ölçek 26 maddeden oluşmaktadır. Veriler araştırmacının uygun olduğu günlerde ilgili kurumlara giderek araştırmaya katılmayı kabul eden personellere anket uygulaması sonucu toplanmıştır. Araştırmaya başlamadan önce Gümüşhane İli Kamu Hastaneler Birliğinden ve Gümüşhane İl Sağlık Müdürlüğ̈̈nden yazılı izin alınmıştır. Ayrıca tüm personellere yapılan araştırma hakkında bilgi verilmiştir. Araştırma kapsamında personelin haklarının korunması için araştırma verilerini toplamaya başlamadan önce personellere araştırmanın amacı ve önemi açıklanarak "Aydınlatılmış Onam " ilkesine, gönüllü olarak araştırmaya katılmayı kabul eden personellerin aynı şekilde istedikleri zaman araştırmadan çekilebilecekleri belirtilerek "Özerklik" ilkesine uyulmuştur. Ayrıca kişisel bilgilerin araştırmacı ile paylaşıldıktan sonra korunacağı söylenerek "Gizlilik ve Gizliliğin Korunması" ilkesine, elde edilen bilgilerin ve cevaplayanın kimliğinin gizli tutulacağı belirtilerek "Kimliksizlik ve Güvenlik" ilkesine uyulmuştur (Erefe, 2012). Zaman ve maliyet kısıtlı olmasından dolayı araştırma sadece Gümüşhane Devlet Hastanesi, Kelkit Devlet Hastanesi, Şiran Devlet Hastanesi, Gümüşhane İl Afet Ve Acil Durum Müdürlüğü, Gümüşhane İl İtfaiye Müdürlüğü, Gümüşhane il merkezi ve ilçelerde bulunan 112 istasyonlarında çalışan sağlık personelleri ile sınırlandırılmış olup, Türkiye genelini kapsayacak şekilde ele alınmamıştır. Bu çalışmanın sonuçları yalnızca kapsam içinde anket uygulananlar için geçerli olup genelleme yapılamaz. Anketin geçerliliği yüzey analizi ile yapıldı. Yüzey geçerliliği 10 hocaya sorularak yapıldı. Gerekli düzenlemeler yapılarak yeniden düzenlenerek onay alındı. Anketin güvenirliği cronbach's alpha ile alındı. Çalışmamızda 26 soru için Cronbach Alpha katsayısı 0.942 olarak bulunmuştur. Verilerin analizinde SPSS 15 paket programı kullanılmıştır. Araştırmada frekans, yüzde, $t$ testi ve varyans testi istatistikleri kullanılmıştır. Anlamlılık düzeyi 0,05 olarak alınmıştır. Bulgularda anlamlı ilişki olan testlere yer verilmiştir. 


\section{Bulgular}

Ankete katılan 140 kişinin 75'i kadın (\%53,6), 65'i ise erkek (\%46,4) tir. Ankete katılan kişilerin medeni durumu incelendiğinde 79 kişi bekar $(\% 56,4)$ olduğu, 61 kişi ise evli $(\% 43,6)$ olduğu gözlemlenmiştir. Ankete katılan kişilerin yaş gurupları göz önüne alındığında 27 kişi 18-22 yaş aralığında olduğu (\%19,3), 49 kişi 23-26 yaş aralığında olduğu (\%54,3), 26 kişi 27-30 yaş aralığında olduğu (\%18,6), 21 kişi 31-35 yaş aralığında olduğu (\%15,0) ve 17 kişi ise 36 yaş ve üstü olduğu anlaşılmaktadır (\%12,1). Ankete katılan 140 kişiden 1 kişi ilkokul mezunu (\%0,7), 4 kişi ortaokul mezunu (\%2,9), 49 kişi lise mezunu (\%35), 86 kişi ise yüksekokul/üniversite (\%61,4) mezunu olduğu anlaşılmaktadır. Ankete katılan kişilerin boylarına baktığımızda 140 kişiden 31'i 1.45-1.60 boyda olduğu (\%22,1), 75 kişi 1.61-1.75 boyda olduğu (\%53,6), 34 kişi ise 1.76-1.90 boyda olduğu (\%24,3) gözlemlenmiştir. Boylar arasında bu kadar fark olmasının nedenlerinden biri anket yapılan bazı meslek gurubunun boy kriterinin olmasıdır. Anket verilerine baktığımızda 140 kişiden 41 kişi 45-60 kilo arasında olduğu (\%29,3), 48 kişi 61-75 kilo arasında olduğu (\%34,3), 46 kişi 76-90 kilo arasında olduğu $(\% 32,9), 5$ kişi ise 91 kilo ve üstü $(\% 3,6)$ olduğu karşımıza çıkmaktadır. Verilere baktığımızda boyda olan kriterlerin kiloda da olduğunu anlıyoruz. Mesleğe girdikten sonra da kilo alanların olduğunu biliyoruz. Ankete katılan 140 kişiden 12'si 1000-1999 TL aldığ1 (\%8,6), 27 kişi 2000-2999 TL aldığ1 (\%19,3), 88 kişi 3000-3999 TL aldığ 1 (\%62,9), 13 kişi ise 4000 TL ve üstü $(\% 9,3)$ aldığ1 karşımıza çıkmaktadır. Ankete katılan 140 kişiden $14^{\prime}$ ü $0-12$ ay mesleğinde çalıştığ $1(\% 10,0)$, 53 kişi 1-4 yıl mesleğinde çalıştı̆̆ $(\% 37,9), 73$ kişi 5 yıl ve üzeri mesleğinde çalıştığı $(\% 52,1)$ karşımıza çıkmaktadır. Anket verilerine baktığımızda 140 kişiden 58'i devlet hastanesinde çalıştı̆̆ $(\% 41,4), 10$ kişi AFAD da çalıştığ $(\% 7,1), 5$ kişi itfaiye de çalıştı̆̆ $(\% 3,6), 67$ kişi ise 112 acil serviste çalıştığ1 $(\% 47,9)$ karşımıza çıkmaktadır. Anket verilerine baktığımızda 140 kişiden 2'si işçi (\%1,4), 16 kişi tekniker (\%11,4), 35 kişi teknisyen (\%25), 2 kişi yönetici (\%1,4), 1 kişi amir (\%0,7), 32 kişi hemşire $(\% 22,9), 5$ kişi şoför $(\% 3,6), 3$ kişi doktor (\%2,1), 13 kişi enformasyon memuru (\%9,3), 31 kişi sağlık memuru $(\% 22,1)$ olduğu ortaya çıkmaktadır. Anket verilerine baktığımızda 140 kişiden 25 'i 8 mesai saati çalıştı ̆̆ $(\% 17,9), 2$ kişi 16 mesai saati çalıştı̆̆ $(\% 1,4), 113$ kişi ise 24 mesai saati $(\% 80,7)$ çalıştığ1 gözlemlenmiştir. Anket verilerine baktığımızda 140 kişiden 108'i 1-4 kişi ile nöbet tutuğu $(\% 77,1)$, 26 kişi 5-9 personelle nöbet tutuğu $(\% 18,6), 6$ kişi 9 personelle nöbet tutuğu $(\% 4,3)$ karşımıza çıkmaktadır. Ayrıca ankete katılan 140 kişiye ilk yardım eğitimi alıp almadıkları sorulduğunda 138 kişi'nin (\%98.6) evet, 2 kişi'nin (\%1.4) hayır cevabı verdikleri gözlemlenmiştir.

"Daha önce ilk yardım eğitimi aldınız mı?" sorusuna evet cevabı veren 138 kişiye ilkyardım eğitimini nereden aldıkları sorulduğunda \% 8,6' 'nın (12 kişi) askerlikte, \% 20,7' sinin (29 kişi) ehliyet kursunda, \% 17,9'unun (25 kişi) ilk yardım merkezlerinde, \% 45,7'sinin (64 kişi) okulda, \% 5.7'sinin (8 kişi) ilk yardım eğitimi diğer kurumlardan aldıkları belirlenmiştir. Çalışma ortamında karşılaştığı problemleri belirten 116 kişiye hangi tür problemle karşılaştığı sorulduğunda \%30.2' sinin (35 kişi) kan ve vücut sıvılarına maruziyet, \% 12.9' unun (15 kişi) kesici ve delici alet yaralanması, \%21.6'sının (25 kişi) şiddet, \%8.6's1 (10 kişi) mobbing, \%6.9'unun (8 kişi) kas ve iskelet sistemi yaralanmaları, \%7.8'inin (9 kişi) enfeksiyon, zehirlenme, elektrik çarpması, \%4.3'ünün (5 kişi) cilt problemleri, \%4.3'ünün (5 kişi) kimyasal maddelere maruziyet, \%1.7'si (2 kişi) trafik kazası, \%0.9'unun (1 kişi) yanık, \%0.9'unun (1 kişi) radyasyona bağlı hastalıklar olduğu saptanmıştır. Çalışanların Mobbing Düzeyi Belirlenmesi Üzerine Tanımlayıcı Analizleri Tablo 1'de görülmektedir. 


\begin{tabular}{|c|c|c|c|c|c|}
\hline SORULAR & 1 & 2 & 3 & 4 & 5 \\
\hline 1.Kendimi ifade etme olanaklarım kısıtlanmaktadır. & 39,3 & 32,9 & 20,7 & 5,7 & 1,4 \\
\hline 2.Sebepsiz yere sözüm kesilmektedir. & 38,6 & 32,9 & 22,9 & 4,3 & 1,4 \\
\hline $\begin{array}{l}\text { 3.İletişim kurma isteğim bakışlar ve imalar yoluyla } \\
\text { reddedilmektedir. }\end{array}$ & 55,7 & 24,3 & 15,7 & 4,3 & 0,0 \\
\hline 4.İyi çalışmama rağmen bana bağırılıyor ve azarlanıyorum. & 73,6 & 17,9 & 5,7 & 0,7 & 2,1 \\
\hline 5.Yaptığım işler sürekli eleştiriliyor. & 61,4 & 25,0 & 10,0 & 2,9 & 0,7 \\
\hline 6.Yazılı veya sözlü olarak tehdit edilmekteyim. & 80,7 & 9,3 & 7,1 & 2,1 & 0,7 \\
\hline $\begin{array}{l}\text { 7.Eğlence ve kutlamalar gibi faaliyetlere kasitlı olarak davet } \\
\text { edilmiyorum. }\end{array}$ & 82,9 & 10,0 & 5,0 & 1,4 & 0,7 \\
\hline 8.İş arkadaşlarım/Üstlerim benimle konuşmuyor. & 85,7 & 10,0 & 2,9 & 0,0 & 1,4 \\
\hline 9.Diğer çalışanlardan ayrı bir yerde çalışmaya zorlanıyorum. & 90,7 & 4,3 & 4,3 & 0,7 & 0,0 \\
\hline 10.Bulunduğum ortamda yokmuşum gibi davraniliyor & 85,7 & 10,0 & 3,6 & 0,7 & 0,0 \\
\hline 11.Hakkımda dedikodular çıkarılıyor ve kötü konuşuluyor & 79,3 & 10,0 & 8,6 & 2,1 & 0,0 \\
\hline $\begin{array}{l}\text { 12.Yürüyüşüm, jestlerim, sesim gülünç duruma düşürülmem için } \\
\text { taklit ediliyor. }\end{array}$ & 89,3 & 6,4 & 3,6 & 0,7 & 0,0 \\
\hline $\begin{array}{l}\text { 13.Psikolojik sorunlarım olduğu yönünde imalı sözler ediliyor, } \\
\text { davranışlar sergileniyor. }\end{array}$ & 93,6 & 2,9 & 2,9 & 0,0 & 0,7 \\
\hline 14.Dini inancımdan / Siyasi görüşümden dolayı alay ediliyorum. & 88,6 & 2,9 & 6,4 & 2,1 & 0,0 \\
\hline $\begin{array}{l}\text { 15.Özgüvenimi veya itibarımı olumsuz etkileyen işleri yapmam } \\
\text { konusunda baskı görüyorum. }\end{array}$ & 90,7 & 5,0 & 3,6 & 0,7 & 0,0 \\
\hline 16. Özel yaşantımla alay ediliyor. & 90,7 & 5,0 & 2,9 & 7 & 0,7 \\
\hline 17.Çabalarım yağcılık olarak değerlendiriliyor. & 90,0 & 5,0 & 3,6 & 1,4 & 0,0 \\
\hline 18.İşle ilgili aldığım kararlar sürekli sorgulanıyor. & 79,3 & 15,0 & 3,6 & 2,1 & 0,0 \\
\hline 19.Alçaltıcı isim ve lakaplarla anılıyorum & 93,6 & 3,6 & 2,1 & 0,7 & 0,0 \\
\hline 20.Verilen görevler geri alınıyor, işim sürekli değiştiriliyor. & 90,7 & 6,4 & 2,9 & 0,0 & 0,0 \\
\hline $\begin{array}{l}\text { 21.Özel bir görev tanımım yok, yapmam için anlamsız işler } \\
\text { veriliyor. }\end{array}$ & 88,6 & 2,9 & 5,7 & 1,4 & 1,4 \\
\hline 22.Özel eşyalarıma zarar veriliyor. & 95,0 & 0,7 & 3,6 & 0,7 & 0,0 \\
\hline 23.Fiziksel olarak ağır işler yapmaya zorlanıyorum & 92,1 & 2,1 & 2,9 & 1,4 & 1,4 \\
\hline 24.Fiziksel şiddet tehditleri alıyorum & 95,0 & 0,7 & 2,9 & 0,7 & 0,7 \\
\hline 25.Cinsel imalarda bulunuluyor. & 97,1 & 0,0 & 2,1 & 0,7 & 0,0 \\
\hline 26.Cinsel tacize uğruyorum. & 97,1 & 0,0 & 2,1 & 0,7 & 0,0 \\
\hline
\end{tabular}

1:Hiçbir zaman; 2:Nadiren; 3:Bazen; 4: Çoğu zaman; 5:Her zaman

Demografik Özellikler İle Mobbing düzeyi arası ilişki olup olmadığını belirlemek için $t$ testi ve varyans testi kullanılmıştır. İlişki analizinde anlamlı düzeyde ilişkili olan değişenlere yer verilmiştir. Diğerlerine bulgularda yer verilmemiştir.

Mobbing durumun cinsiyet açısından farklı olup olmadığının belirlenmesi için $t$ testi yapılmış ve sonuçlar tablo 2 ' de verilmiştir.

Tablo 2. Cinsiyet ile Mobbing Düzeyi Arası İlişki (t testi sonuçları)

\begin{tabular}{|c|c|c|c|}
\hline SORULAR & Cinsiyet & Ortalama & $\begin{array}{l}\text { Anlamlılık } \\
\text { Düzeyi }\end{array}$ \\
\hline \multirow{2}{*}{$\begin{array}{l}\text { İletişim kurma isteğim bakışlar ve imalar } \\
\text { yoluyla reddedilmektedir. }\end{array}$} & Kadın & 1,5467 & \multirow[t]{2}{*}{,044 } \\
\hline & Erkek & 1,8462 & \\
\hline \multirow{2}{*}{$\begin{array}{l}\text { Bulunduğum ortamda yokmuşum gibi } \\
\text { davranilıyor. }\end{array}$} & Kadın & 1,1067 & \multirow[t]{2}{*}{,030 } \\
\hline & Erkek & 1,2923 & \\
\hline \multirow{2}{*}{$\begin{array}{l}\text { Hakkımda dedikodular çıkarılıyor ve } \\
\text { kötü konuşuluyor. }\end{array}$} & Kadın & 1,1467 & \multirow[t]{2}{*}{,001 } \\
\hline & Erkek & 1,5538 & \\
\hline \multirow{2}{*}{$\begin{array}{l}\text { Yürüyüşüm, jestlerim, sesim gülünç } \\
\text { duruma düşürülmem için taklit ediliyor. }\end{array}$} & Kadın & 1,0800 & \multirow[t]{2}{*}{043} \\
\hline & Erkek & 1,2462 & \\
\hline \multirow{2}{*}{$\begin{array}{l}\text { Dini inancımdan / Siyasi görüşümden } \\
\text { dolayı alay ediliyorum. }\end{array}$} & Kadın & 1,1200 & \multirow[t]{2}{*}{,043 } \\
\hline & Erkek & 1,3385 & \\
\hline
\end{tabular}




\begin{tabular}{|l|l|l|c|}
\hline & & & \\
\hline \multirow{2}{*}{$\begin{array}{l}\text { Özgüvenimi veya itibarımı olumsuz } \\
\text { etkileyen işleri yapmam konusunda } \\
\text { baskı görüyorum. }\end{array}$} & Kadın & 1,0667 & \multirow{2}{*}{041} \\
\cline { 2 - 3 } & Erkek & 1,2308 & \\
\hline Özel yaşantımla alay ediliyor. & Kadın & 1,0667 & \multirow{2}{*}{037} \\
\cline { 2 - 3 } & Erkek & 1,2615 & \\
\hline \multirow{2}{*}{$\begin{array}{l}\text { Özel bir görev tanımım yok, yapmam } \\
\text { için anlamsız işler veriliyor. }\end{array}$} & Kadın & 1,1200 & \multirow{2}{*}{, 031} \\
\cline { 2 - 3 } & Erkek & 1,3846 & \multirow{2}{*}{, 030} \\
\hline Cinsel tacize uğruyorum. & Kadın & 1,0000 & \\
\cline { 2 - 3 } & Erkek & 1,1385 & \\
\hline
\end{tabular}

Eğitim durumu ile acil durum ve afet müdahale çalışanlarının sahada karşılaştıkları mobbing düzeyi arasında iki soruda anlamlı bir ilişki bulunmuştur (Tablo 3)

Tablo 3. Eğitim Durumu İle Mobbing Düzeyi Arasındaki İlişki Düzeyi (Anova sonuçları)

\begin{tabular}{|c|c|c|c|c|}
\hline SORULAR & Eğitim Durumu & \begin{tabular}{|l|} 
Kişi \\
Sayı1sı
\end{tabular} & Ortalama & $\begin{array}{l}\text { Anlamlılık } \\
\text { Düzeyi }\end{array}$ \\
\hline \multirow{4}{*}{ Çabalarım yağcılık olarak değerlendiriliyor } & İlkokul mezunu & 1 & 1,0000 & \multirow{4}{*}{,003 } \\
\hline & $\begin{array}{l}\text { Ortaokul ve dengi okul } \\
\text { mezunu }\end{array}$ & 4 & 2,0000 & \\
\hline & Lise ve dengi okul mezunu & 49 & 1,1633 & \\
\hline & $\begin{array}{l}\text { Yüksekokul/üniversite } \\
\text { mezunu }\end{array}$ & 86 & 1,1279 & \\
\hline \multirow{4}{*}{$\begin{array}{l}\text { İşle ilgili aldığım kararlar sürekli } \\
\text { sorgulanıyor. }\end{array}$} & İlkokul mezunu & 1 & 1,0000 & \multirow{4}{*}{,000 } \\
\hline & $\begin{array}{llll}\begin{array}{l}\text { Ortaokul ve dengi okul } \\
\text { mezunu }\end{array} & & & \\
\end{array}$ & 4 & 2,7500 & \\
\hline & Lise ve dengi okul mezunu & 49 & 1,2041 & \\
\hline & $\begin{array}{l}\text { Yüksekokul/üniversite } \\
\text { mezunu }\end{array}$ & 86 & 1,2674 & \\
\hline
\end{tabular}

Gelir düzeyi ile acil durum ve afet müdahale çalışanlarının sahada karşılaştıkları mobbing düzeyi arasında iki soruda anlamlı bir ilişki bulunmuştur (Tablo 4).

Tablo 4. Gelir Durumu İle Mobbing Düzeyi Arasındaki İlişki Düzeyi (Anova Sonuçları)

\begin{tabular}{|c|c|c|c|c|}
\hline SORULAR & Gelir Durumu & Kişi Sayısı & Ortalama & Anlamlılık Düzeyi \\
\hline \multirow{4}{*}{$\begin{array}{l}\text { İş arkadaşlarım/Üstlerim benimle } \\
\text { konuşmuyor. }\end{array}$} & $1000-1999 \mathrm{TL}$ & 12 & 1,2500 & \multirow{4}{*}{,001 } \\
\hline & 2000-2999 TL & 27 & 1,0741 & \\
\hline & 3000-3999 TL & 88 & 1,1591 & \\
\hline & 4000 TL ve üstü & 13 & 1,8462 & \\
\hline \multirow[t]{4}{*}{ Cinsel imalarda bulunuluyor. } & $1000-1999 \mathrm{TL}$ & 12 & 1,0000 & \multirow{4}{*}{, 014} \\
\hline & $2000-2999 \mathrm{TL}$ & 27 & 1,0000 & \\
\hline & 3000-3999 TL & 88 & 1,0455 & \\
\hline & 4000 TL ve üstü & 13 & 1,3846 & \\
\hline
\end{tabular}

Çalışma saatleri ile acil durum ve afet müdahale çalışanlarının sahada karşılaştıkları mobbing düzeyi arasında 7 soruda anlamlı bir ilişki bulunmaktadır (Tablo 5) 
Tablo 5. Çalışma Saatleri İle Mobbing Düzeyi Arasındaki İlişki Düzeyi (Anova Sonuçları)

\begin{tabular}{|c|c|c|c|c|}
\hline & $\begin{array}{l}\text { Çalışma } \\
\text { Saatleri }\end{array}$ & Kişi Sayısı & Ortalama & Anlamlılık Düzeyi \\
\hline \multirow{3}{*}{$\begin{array}{l}\text { İletişim kurma isteğim bakışlar ve imalar } \\
\text { yoluyla reddedilmektedir. }\end{array}$} & 8 saat & 25 & 1,4000 & \multirow{3}{*}{,004 } \\
\hline & 16 saat & 2 & 3,5000 & \\
\hline & 24 saat & 113 & 1,7168 & \\
\hline \multirow{3}{*}{$\begin{array}{l}\text { İyi çalışmama rağmen bana bağırılıyor ve } \\
\text { azarlanıyorum. }\end{array}$} & 8 saat & 25 & 1,1600 & \multirow{3}{*}{047} \\
\hline & 16 saat & 2 & 2,5000 & \\
\hline & 24 saat & 113 & 1,4336 & \\
\hline \multirow{3}{*}{$\begin{array}{l}\text { Özgüvenimi veya itibarımı olumsuz } \\
\text { etkileyen işleri yapmam konusunda baskı } \\
\text { görüyorum. }\end{array}$} & 8 saat & 25 & 1,2000 & \multirow{3}{*}{,031 } \\
\hline & 16 saat & 2 & 2,0000 & \\
\hline & 24 saat & 113 & 1,1150 & \\
\hline \multirow[t]{3}{*}{ Alçaltıcı isim ve lakaplarla anılıyorum } & 8 saat & 25 & 1,1600 & \multirow{3}{*}{,000 } \\
\hline & 16 saat & 2 & 2,5000 & \\
\hline & 24 saat & 113 & 1,0619 & \\
\hline \multirow{3}{*}{ Özel eşyalarıma zarar veriliyor. } & 8 saat & 25 & 1,1600 & \multirow{3}{*}{,000 } \\
\hline & 16 saat & 2 & 2,5000 & \\
\hline & 24 saat & 113 & 1,0619 & \\
\hline \multirow[t]{3}{*}{ Fiziksel şiddet tehditleri alıyorum. } & 8 saat & 25 & 1,1600 & \multirow{3}{*}{,001 } \\
\hline & 16 saat & 2 & 2,5000 & \\
\hline & 24 saat & 113 & 1,0796 & \\
\hline \multirow[t]{3}{*}{ Cinsel imalarda bulunuluyor. } & 8 saat & 25 & 1,2000 & \multirow{3}{*}{,000 } \\
\hline & 16 saat & 2 & 2,0000 & \\
\hline & 24 saat & 113 & 1,0177 & \\
\hline
\end{tabular}

Çalıştığı kurum ile acil durum ve afet müdahale çalışanlarının sahada karşılaştıkları mobbing düzeyi arasında iki soruda anlamlı bir ilişki bulunmuştur (Tablo 6).

Tablo 6. Çalışılan Kurum İle Mobbing Düzeyi Arasındaki İlişki Düzeyi (Anova Sonuçları)

\begin{tabular}{|c|c|c|c|c|}
\hline SORULAR & Çalıştı̆̆1 Kurum & Kişi Sayısı & Ortalama & Anlamlılık Düzeyi \\
\hline \multirow{4}{*}{$\begin{array}{l}\text { İş arkadaşlarım/Üstlerim } \\
\text { benimle konuşmuyor. }\end{array}$} & Devlet hastanesi & 58 & 1,3103 & \multirow{4}{*}{,045 } \\
\hline & AFAD & 10 & 1,1000 & \\
\hline & İtfaiye & 5 & 1,8000 & \\
\hline & 112 & 67 & 1,1045 & \\
\hline \multirow{4}{*}{$\begin{array}{l}\text { İşle ilgili aldığım kararlar } \\
\text { sürekli sorgulanıyor }\end{array}$} & Devlet hastanesi & 58 & 1,3103 & \multirow{4}{*}{,003 } \\
\hline & AFAD & 10 & 1,9000 & \\
\hline & İtfaiye & 5 & 1,6000 & \\
\hline & 112 & 67 & 1,1493 & \\
\hline
\end{tabular}

\section{Sonuç ve Değerlendirme}

Çalışanların mobbing düzeyi ile ilgili 26 sorudan elde edilen algılamalarına bakıldığında; 'özel eşyalarıma zarar veriliyor', 'fiziksel olarak ağır işler yapmaya zorlanıyorum',' fiziksel şiddet tehditleri alıyorum', 'cinsel imalarda bulunuluyor', ' cinsel tacize uğruyorum', 'psikolojik sorunlarım olduğu yönünde imalı sözler ediliyor', 'diğer çalışanlardan ayrı bir yerde çalışmaya zorlanıyorum', 'özgüvenimi veya itibarımı olumsuz etkileyen işleri yapmam konusunda baskı görüyorum', 'özel yaşantımla alay ediliyor', 'çabalarım yağcılık olarak değerlendiriliyor', 'alçaltıcı isim ve lakaplarla anılıyorum', 'verilen görevler geri alınıyor', 'işim sürekli değiştiriliyor' sorularına deneklerin \%90'nın üzerinde 'hiçbir zaman' şeklinde yanıt veriliyor. 7 soruda \%80 nin üzerinde 'hiçbir zaman' şeklinde yanıt veriliyor. 3 soruda \%70' in üzerinde 'hiçbir zaman' şeklinde cevap verliyor. 4 soruda 'nadiren' ve ' bazen' oranları yüksek sayılacak düzeydedir. Bunlar; 'yaptığım 
işler sürekli eleştiriliyor', 'kendimi ifade etme olanaklarım kısıtlanmaktadır', 'iletişim kurma isteğim bakışlar ve imalar yoluyla reddedilmektedir', 'sebepsiz yere sözüm kesilmektedir'. Bu durum genelde birçok işyerinde geçerli olan şikayetler olup, diğer mobbing sorularına göre psikolojik tüketme düzeyleri daha düşüktür. Mesela, cinsel imalarda bulunulması, cinsel tacize uğranılması, alçaltıcı lakaplar ve isimler takılması, özel yaşantıyla alay edilmesi, fiziksel şiddet tehditleri alınması, dini inançtan/siyasi görüşten dolayı alay edilmesi, insan hakkında dedikodular çıkartılması ve kötü konuşulması, yazılı veya sözlü olarak tehdit edilmek gibi olan davranışlar insanı daha çok tüketir. Araştırma kapsamındaki bireylerde bireyin psikolojisini tüketen bu gibi ağır davranış tarzlarının olmadığı ama diğer birçok işyerinde görülebilecek görece daha hafif kötü davranış tarzları görülmektedir. Genel olarak 26 soruya bakıldığında deneklerin mobbing uğrama düzeylerinin çok düşük olduğu görülmektedir.

Çalışanların mobbinge uğrama düzeyleri çok düşük olsa bile, mobbing düzeyinin demografik değişkenlere göre farklılık gösterip göstermediğine ilişkin yapılan testlerde bazı sonuçlara ulaşılmıştır. Farklılık gösteren değişkenlerden birisi cinsiyet değişkenidir. Cinsiyet değişkenine göre mobbing düzeyi farklılı̆̆ını belirlemek için yapılan $t$ testi sonucu aşağıdaki sorulara erkeklerin yüksek düzeyde katıldıkları görülmüştür. Bunlar; 'iletişim kurma isteğim bakışlar ve imalar yoluyla reddedilmektedir', 'bulunduğum ortamda yokmuşum gibi davranılıyor', 'hakkımda dedikodular çıkarılıyor ve kötü konuşuluyor', 'yürüyüşüm, jestlerim, sesim gülünç duruma düşürülmem için taklit ediliyor', 'dini inancımdan/siyasi görüşümden dolayı alay ediliyorum', 'özgüvenimi veya itibarımı olumsuz etkileyen işleri yapmam konusunda baskı görüyorum', 'özel yaşantımla alay ediliyor', 'özel bir görev tanımım yok', 'yapmam için anlamsız işler veriliyor', 'cinsel tacize uğruyorum'. Bu sorulardan sadece 'cinsel tacize' uğruyorum sorusuna verieln cevap şaşırtıcı gelmiştir. Çünkü cinsel tacize uğrama sorusuna kadınların daha fazla katılmaları beklenirken erkeklerin daha fazla cinsel tacize uğradıkları görülmüştür. Fakat unutulmaması gereken çok nadiren gerçekleştiği belirtilen sorulara verilen cevaplar arası farkları tespit ediyoruz. Bu sonuçlar araştırma kapsamında sadece istisnai durumlardır.

Eğitim durumu ile acil durum ve afet müdahale çalışanlarının sahada karşılaştıkları mobbing düzeyi arasında iki soruda anlamlı bir ilişki bulunmuştur, Bunlar: 'çabalarım yağcılık olarak değerlendiriliyor' ve 'işle ilgili aldığım kararlar sürekli sorgulanıyor'. Araştırma kapsamında ilkokul mezunu 1 kişi ve ortaokul ve dengi okul mezunu 4 kişi olduğu için yapılan Anova testi sonuçları anlamlı çıksa bile yorumlarken dikkatli olunması gerekmektedir. Bu iki soruya düşük eğitim seviyesindeki kişilerin daha çok katıldıkları görülmektedir. Diğer yandan çıkan sonuç tecrübeden elde edilen verilere uymaktadır. Gerçekten de eğitim seviyesi yüksek olanların eğitim seviyesi düşük olanların kararlarını sorgulamaları sıkça görülebilir bir durumdur.

Gelir düzeyi ile acil durum ve afet müdahale çalışanlarının sahada karşılaştıkları mobbing düzeyi arasında iki soruda anlamlı bir ilişki bulunmuştur. Bunlar: 'iş arkadaşlarım/üstlerim benimle konuşmuyor' ve 'cinsel imalarda bulunuluyor'. Her iki soruda da gelir düzeyi en yüksek olanların daha yüksek puan verdikleri görülmektedir. Gelir düzeyi yüksek olanların neden bu iki soruya daha yüksek puan verdikleri psikolojik açıdan derinlemesine araştırılması gereken bir konudur. Her iki soruda kuruntu gibi algilanabilir sorulardır.

Çalışma saatleri ile acil durum ve afet müdahale çalışanlarının sahada karşılaştıkları mobbing düzeyi arasında 7 soruda anlamlı bir ilişki bulunmaktadır. Bunlar: 'iletişim kurma isteğim bakışlar ve imalar yoluyla reddedilmektedir', 'iyi çalışmama rağmen bana bağırılıyor ve azarlanıyorum', 'özgüvenimi veya itibarımı olumsuz etkileyen işleri yapmam konusunda baskı görüyorum', 'alçaltıcı isim ve lakaplarla anılıyorum', 'özel eşyalarıma zarar veriliyor', 'fiziksel şiddet tehditleri alıyorum', 'cinsel imalarda bulunuluyor'. Bu sorularda 8 saat ve 24 saat şeklinde çalışanlar daha düşük düzeyde cevap verirlerken 16 saat çalışanlar ise daha yüksek seviyede cevap vermektedirler. 8 saat çalışanlar ve 24 saat usulü çalışanların 16 saat çalışanlara göre daha az yıprandıkları söylenebilir. Çünkü 24 saat usulü çalışanların sonraki günleri izin günleridir. Bu durumda en fazla yıprananlar 16 saat usulü çalışanlardır. Fazla çalışmadan dolayı psikolojileri yıpranan kişiler hem tehdit hissini daha fazla algılarken diğerlerine karşı yıpranmadan dolayı daha tehditkar davranmaları olağandır. Burda bulunulan farklılıkların toptan bir şekilde değerlendirilmesi daha 
tutarlı olacaktır. Çünkü çalışma saatleri ile mobbing düzeyi arasında ilişki sorular bazında ele alındığında matıklı bir sonuca ulaşılamıyor. Fakat toplu şekilde sorular ele alındığında daha uzun ve arasız çalışanların mobbing sorularına daha yüksek düzeyde puan vermeleri işi yükünün oluşturduğu psikoljik algılama şekillerindeki değişim olabilir.

Çalıştığ kurum ile acil durum ve afet müdahale çalışanlarının sahada karşılaştıkları mobbing düzeyi arasında iki soruda anlamlı bir ilişki bulunmuştur. 'İş arkadaşlarım/üstlerim benimle konuşmuyor' sorusuna İtfaiye çalışanları diğerlerine göre daha yüksek puanlama yapmışlardır. 'İşle ilgili aldığım kararlar sürekli sorgulanıyor' sorusuna ise AFAD çalışanları daha yüksek puanlamıştır. Bu sonuçlar işyeri ortamıyla ilişki olabileceği gibi, genel anlamda da ele alınmamalıdır. Araştırma kapsamındaki denek sayısının az olması ve düşük puanlama düzeyinde farklılıkların araştırılması gibi istatistiksel nedenlerden dolayı bu sonucun yorumlanmaması daha uygun olacaktır. Bu sonucun gerçek sebebi anlaşılacaksa ilgili kurumlarda niteliksel araştırma yapmak gerekmektedir.

\section{Kaynakça}

Demirbulat, Ö.G. (2012). İşgörenlerin mobbinge maruz kalma durumları: Trabzon ili a grubu seyahat acenteleri örneği. Karadeniz Teknik Üniversitesi İletişim Araştırmaları Dergisi, 2(4), 27-40.

Fattahlığlu, Ö.O. (2008). Örgütlerde psikolojik şiddet (mobbing): üniversitelerde bir uygulama. Yayınlanmamış doktora tezi, Dokuz Eylül Üniversitesi Sosyal Bilimler Enstitüsü İşletme Anabilimdalı, İzmir.

Gültekin, N. \& Deniz, Z. (2016). İşyerinde mobbing: çalışanlar üzerine yapılan bir araştırma. İktisadi İdari veSiyasal Araştırmalar Dergisi,1(1),1-11.

Karçın, M. (2016). 112 Acil sağhlk hizmetlerinde mobbing ve ilişkili faktörler: Aydın ili örneği, yayınlanmamış yüksek lisans tezi, Kocaeli Üniversitesi Sağlık Bilimleri Enstitüsü, Kocaeli.

Kehribar, A., Karabela, Ş.N. \& Çankaya, F. (2017). Çalışma hayatında mobbing: nedenleri, bileşenleri ve ülkemizdeki hukuki durumu. Bakırköy Tip Dergisi, 13(1), 1-9.

Özkul, B. \& Çarıkçı İ.H. (2010). Mobbing ve türk hukuku açısından değerlendirilmesi. Süleyman Demirel Üniversitesi İktisadi ve İdari Bilimler Fakültesi Dergisi, 15(1), 481-499.

Öztürk H., Dereli, E.E., \& Faikoğlu, R. (2015), Mobbing (psikolojik yıldırma), örgüt üzerindeki etkileri ve çözüm önerileri. Sağhlk Akademisyenleri Dergisi, 2(1), 27-33.

Polat, O. \& Pakiş, I. (2012). Mobbing: işyerinde psikolojik taciz. Acıbadem Üniversitesi Sağlık Bilimleri Dergisi, 3(4), 211-217.

Tetik, S. (2010). Mobbing kavramı: birey ve örgütler açısından önemi. KMÜ Sosyal ve Ekonomik Araştırmalar Dergisi, 12 (18), 81-89.

Tinaz, P. (2006). Mobbing: işyerinde psikolojik taciz. Çalışma ve Toplum Dergisi, 3(10), 11-22.

Turan, M., Cengiz, E., \& Cengiz, S. (2015). A study on the relationship between the strategies of conflict management and the leadership styles of emergency, rescue and intervention employees: An example of Erzurum province. Int. J. Eco. Res, 6(1), 99-111.

\section{Aim and Scope}

\section{Extended Abstract}

This research was conducted to determine the level of mobbing that emergency and disaster response workers are exposed to and to determine whether the mobbing level differs according to demographic variables.

\section{Methodology}

The population of the research is 332 people working in Gümüşhane State Hospital, Kelkit State Hospital, Şiran State Hospital, Gümüşhane Provincial Directorate of Disaster and Emergency, Gümüşhane Provincial Fire Department, Gümüşhane city center and 112 stations in the districts of Gümüşhane Public Hospitals Association (GKHB). The survey was conducted between 08/05/2017 - 22/05/2017 and a total of 140 people were included in the analysis. As a result of the analysis, it was determined that the mobbing perception levels of the employees within the scope of the study were very low. Perception levels of mobbing differ according to gender, education level, income 
level, working hours and the institution they work for. The low level of perception of mobbing caused difficulties in the interpretation of group differences at this level, and generalization was not made. In the data collection, the "Personal Information Form and the Scale for Determining the Mobbing Level of Emergency and Disaster Response Personnel", which was created by the researcher in accordance with the literature information, were used. It was collected by going to face-to-face interview technique.

\section{Findings and Conclusion}

Considering the perceptions of the employees obtained from 26 questions about the level of mobbing; 'My personal belongings are damaged', 'I am forced to physically do heavy work', 'I am receiving threats of physical violence', 'I am sexually inferred', 'I am being sexually harassed', 'I am subjected to psychological problems', 'I am forced to work in a place', 'I am under pressure to do jobs that negatively affect my self-esteem or reputation', 'my private life is mocked', 'my efforts are considered as flattering', 'I am known with degrading names and nicknames',' my job is being taken back ',' my job is constantly over $90 \%$ of the subjects are answered as 'never'. Over $80 \%$ of 7 questions are answered as 'never'. Over $70 \%$ of 3 questions answered as "never". 'Rarely' and 'sometimes' rates are at a high level in 4 questions. These; "My work is constantly criticized", "My opportunities to express myself are restricted", "My desire to communicate is rejected through glances and insinuations", "I am interrupted for no reason". This is generally a complaint in many workplaces, and psychological consumption levels are lower than other mobbing questions. For example, sexual innuendo, being sexually harassed, using derogatory nicknames and names, being ridiculed by private life, receiving threats of physical violence, being ridiculed for religious belief / political opinion, gossiping and spoken about people, being threatened in writing or verbally. behaviors consume more people. It is observed in the individuals within the scope of the study that there are no such heavy behavior styles that consume the individual's psychology, but relatively mild bad behavior styles that can be seen in many other workplaces. When looking at 26 questions in general, it is seen that the level of mobbing of the subjects is very low. Even if the level of mobbing of the employees is very low, some results were obtained in the tests conducted on whether the level of mobbing differs according to demographic variables. One of the variables that show difference is the gender variable. As a result of the $t$ test performed to determine the difference in the level of mobbing according to the gender variable, it was observed that the males agreed with the following questions at a high level. These; 'my willingness to communicate is denied through glances and implications',' I am treated as if I am not in my environment ',' I am rumored and spoken badly ',' my walk, my gestures, my voice are imitated to make me ridiculous', 'my religious belief / political view is mocked 'I am under pressure to do things that negatively affect my self-esteem or reputation', 'I am mocked by my private life', 'I have no specific job description', 'I am being given meaningless work to do', 'I am being sexually harassed'. The answer given only to the question of "I am being sexually harassed" came as surprising. Because it was observed that women were expected to participate more in the question of sexual harassment, while men were more exposed to sexual harassment. However, we identify the differences between the answers given to the questions that are stated to occur very rarely, which should not be forgotten. These results are only exceptional cases within the scope of the research. A meaningful relationship was found between the educational status and the level of mobbing faced by emergency and disaster response workers in the field, in two questions. These are: 'my efforts are considered to be flattery' and 'my work-related decisions are constantly being questioned'. Even if the Anova test results are found to be meaningful, since there is 1 primary school graduate and 4 secondary school graduates within the scope of the study, it is necessary to be careful when interpreting it. It is seen that people with low education level agree more to these two questions. On the other hand, the result fits the data obtained from experience. Indeed, it is common for those with a high level of education to question the decisions of those with a low level of education. In two questions, a significant relationship was found between the level of income and the level of mobbing emergency and disaster response workers encountered in the field. These are: 'my colleagues / superiors are not talking to me' and 'sexual innuendo'. In both questions, it is seen that those with the highest income level give higher scores. Why people with high income 
give higher scores to these two questions is an issue that needs to be investigated in depth psychologically. Both questions are perceivable as delusions. There is a significant relationship in 7 questions between working hours and the level of mobbing emergency and disaster response workers encounter in the field. These are: 'My desire to communicate is denied through glances and insinuations', 'I am shouted and scolded at me despite my good work', 'I am bothered about doing things that negatively affect my self-esteem or reputation'. 